\title{
Blood pressure, arterial compliance, and left ventricular mass: no relation to small size at birth in south Indian adults
}

\author{
K Kumaran, C H D Fall, C N Martyn, M Vijayakumar, C Stein, R Shier
}

\begin{abstract}
Objective-To determine whether reduced fetal growth leads to raised blood pressure, reduced arterial compliance, and increased left ventricular mass in an Indian population.

Design-A retrospective cohort study of men and women (age range 40-61 years) whose weight, length, and head circumference at birth were recorded.

Setting-The Holdsworth Memorial Hospital, Mysore, South India.

Subjects-435 men and women born in the hospital between 1934 and 1953.

Main outcome measures-Systolic and diastolic blood pressures; compliance in four arterial segments derived from pulse wave velocity, measured by a non-invasive optical method; and left ventricular mass measured using $M$ mode echocardiography.

Results-Small size at birth was not associated with increased adult blood pressure or left ventricular mass, or with reduced arterial compliance. Systolic blood pressure and left ventricular mass were higher in subjects who were greater in length at birth, rising by $1.64 \mathrm{~mm} \mathrm{Hg}(95 \%$ confidence interval (CI) -0.08 to $+3.37 \mathrm{~mm} \mathrm{Hg}$ ) and $1.63 \mathrm{~g} / \mathrm{m}^{2}\left(95 \% \mathrm{CI} 0.13\right.$ to $\left.3.13 \mathrm{~g} / \mathrm{m}^{2}\right)$, respectively, per one inch $(2.5 \mathrm{~cm})$ increase in birth length, independently of adult size. Arterial compliance was reduced in people whose mothers were lighter and had smaller pelvic (external conjugate) diameters.

Conclusions-The higher prevalence of coronary heart disease in Indian men and women of lower birth weight, shown in an earlier study of the same cohort, cannot be explained by changes in blood pressure, arterial compliance, and left ventricular mass. The association of raised blood pressure and left ventricular mass with longer birth length suggests that the way in which the intrauterine environment influences coronary heart disease differs between Indian and Western populations.
\end{abstract}

(Heart 2000;83:272-277)

Keywords: birth size; blood pressure; arterial compliance; left ventricular mass

Holdsworth Memorial Hospital, Mysore, India

K Kumaran

MRC Environmental Epidemiology Unit, Southampton, UK C H D Fall

C N Martyn

Vijaya Heart

Foundation, Vijaya

Hospitals, Chennai, India

M Vijayakumar

Southampton and South West Hampshire Health Authority, Southampton, UK

C Stein

London School of Hygiene and Tropical Medicine, London, UK R Shier

Correspondence to: Dr K Kumaran, MRC Environmental Epidemiology Unit, Southampton General Hospital, Southampton SO16 6YD, UK

email: kk@mrc.soton.ac.uk

Accepted 12 October 1999
Studies in Britain, Europe, and the USA have shown that low birth weight and other indices of reduced fetal growth are associated with an increased risk of coronary heart disease in adult life. ${ }^{1-3}$ Small size at birth is also associated with risk factors for the disease, including hypertension, reduced arterial compliance, increased left ventricular mass, raised serum lipids, insulin resistance, and non-insulin dependent diabetes mellitus. ${ }^{4-9}$ These findings have led to the "fetal origins" hypothesis, that the pathophysiological mechanisms leading to coronary heart disease are initiated by undernutrition in utero. ${ }^{10}$

Rates of fetal growth are low in India. The mean birth weight is $2.7 \mathrm{~kg}$, and one third of babies are born with a low birth weight $(<2.5 \mathrm{~kg}) .{ }^{11}$ The prevalence of coronary heart disease is rising rapidly in India, and is expected to become the leading cause of death by the year $2020 .^{12}$ This phenomenon is not explained by high levels of classical risk factors including high blood pressure, smoking, and hypercholesterolaemia. ${ }^{13}$ The "fetal origins" hypothesis may therefore be particularly relevant to India.

In a study in Mysore in 1993, low birth weight, short birth length, and small head circumference at birth were associated with an increased prevalence of adult coronary heart disease in an Indian population. ${ }^{14}$ In addition, rates of disease were higher in people whose mothers had a low body weight in pregnancy. It is important to study this Indian population to define mechanisms linking poor fetal growth to adult disease. We have now re-examined these men and women to test the hypothesis that the link between reduced fetal growth and coronary heart disease is mediated by changes in blood pressure, arterial compliance, and left ventricular mass.

\section{Methods}

Since 1934 the Holdsworth Memorial Hospital, Mysore, south India has maintained obstetric records documenting the weight, length, and head circumference at birth for all babies born there. For cases where the mother attended the antenatal clinic (approximately $40 \%$ ) maternal weight at booking was recorded. External pelvimetry was measured on admission to the labour ward for most primiparous and some multiparous mothers.

In an earlier study we traced 517 men and women who were born in the hospital between 1934 and 1953, still lived in Mysore, and could be matched with certainty to their birth records. ${ }^{14}$ Cases of coronary heart disease $(n=52)$ were defined by the presence of one or more of the following: typical angina according 
to the Rose/World Health Organisation chest pain questionnaire ${ }^{15}$; ECG Minnesota codes ${ }^{16}$ 1-1 or 1-2 ( $Q$ and QS waves) in a standard 12 lead ECG; or a history of coronary angioplasty or bypass graft surgery. Information on smoking habits, alcohol consumption, physical activity, and socioeconomic status were obtained by questionnaire.

In 1996-97, we recontacted the same men and women, and invited them for further cardiovascular studies. All measurements were carried out by one observer (KK). A questionnaire was administered to obtain information on current medications. Weight was measured to the nearest $0.5 \mathrm{~kg}$ using a Seca scale (CMS Instruments, London, UK). Height was measured to the nearest $0.1 \mathrm{~cm}$ using a portable Harpenden stadiometer (CMS Instruments). Body surface area was calculated using a standard formula. ${ }^{17}$ Systolic and diastolic blood pressures were recorded using an automated device (Dinamap 8100; Critikon, Ascot, Berks, UK) and a cuff of appropriate size for the subject's mid-upper arm circumference. Measurements were made on the right arm, left arm, and right leg, with the subject supine and rested for at least 10 minutes. Subjects were defined as hypertensive if they had a right arm systolic pressure $>140 \mathrm{~mm} \mathrm{Hg}$, or a diastolic pressure $>90 \mathrm{~mm} \mathrm{Hg}{ }^{18}$ or were taking antihypertensive medication.

\section{ARTERIAL COMPLIANCE}

Arterial compliance was measured in four arterial segments (right and left aortoradial, right aortofemoral, and aortoposterior tibial) using a non-invasive optical method. ${ }^{19}$ This is based on the principle that pulse wave velocity is increased in stiffer (less compliant) arteries. The time delay between left ventricular contraction, recorded by ECG, and the arrival of the pressure wave in a distal artery, recorded by an infra red probe is measured using customised software. Measurement of the distance from the heart (sternal notch) to the probe allows pulse wave velocity to be calculated. This method has been validated against intra-arterial measurements of pressure wave velocity, and gives similar estimates of arterial compliance to those obtained by Doppler ultrasound..$^{19}$

LEFT VENTRICULAR MASS

Left ventricular mass was measured using two dimensional and $M$ mode echocardiography

Table 1 Mean (SD) characteristics of the Mysore men and women

\begin{tabular}{|c|c|c|c|}
\hline & Male $(n=237)$ & Female $(n=198)$ & All $(n=435)$ \\
\hline Current age (years) & $49.5 \quad(4.8)$ & $49.5 \quad(4.8)$ & $49.5(4.8)$ \\
\hline Weight (kg) & $63.3(12.4)$ & $58.5(13.0)$ & $61.1 \quad(12.9)$ \\
\hline Height $(\mathrm{cm})$ & $165.5(6.1)$ & $151.6(6.5)$ & $159.2(9.4)$ \\
\hline Body mass index $\left(\mathrm{kg} / \mathrm{m}^{2}\right)$ & $23.1(4.0)$ & $25.4(5.1)$ & 24.1 \\
\hline Body surface area $\left(\mathrm{m}^{2}\right)$ & $1.68(0.17)$ & $1.52(0.17)$ & $1.61(0.19)$ \\
\hline$\%$ current smokers & 47 & 0 & 26 \\
\hline$\%$ ex-smokers & 15 & 0 & 8 \\
\hline$\%$ alcohol consumption & 21 & 0 & 12 \\
\hline \multicolumn{4}{|l|}{ At birth } \\
\hline Birth weight $(\mathrm{g})$ & 2785 & $(401)$ & 2749 \\
\hline Length $(\mathrm{cm})$ & $47.9(3.1)$ & $47.6 \quad(3.0)$ & $47.8 \quad(3.0)$ \\
\hline Head circumference $(\mathrm{cm})$ & $33.7(1.7)$ & $33.2(1.6)$ & $33.5 \quad(1.7)$ \\
\hline Ponderal index $\left(\mathrm{g} / \mathrm{cm}^{3}\right)$ & $25.7 \quad(5.0)$ & $25.4 \quad(5.0)$ & $25.6(5.0)$ \\
\hline
\end{tabular}

(Larsen and Toubro Sigma 1AC or Clarity machine with a $3.5 \mathrm{~Hz}$ transducer), according to the recommendations of the American Society of Echocardiography. ${ }^{20}$ Interventricular septal thickness and posterior cardiac wall thickness at end diastole, and left ventricular internal diameter at end diastole and systole, were measured from $M$ mode prints using a digitiser (Genitiser GT-1212B, Taipei, Taiwan). The average measurements from five cardiac cycles were used for the analysis. Left ventricular mass and relative wall thickness were calculated using standard formulae. ${ }^{21}$

Analyses were carried out using left ventricular mass as a continuous variable, and also as a dichotomous variable - the presence or absence of left ventricular hypertrophy. To define left ventricular hypertrophy for this population, we considered a "normal" subgroup of people without hypertension, coronary heart disease or diabetes and with a body mass index $<30 \mathrm{~kg} / \mathrm{m}^{2}$. Subjects who had a left ventricular mass (indexed by body surface area) $>2$ SDs from the sex specific mean were defined as having left ventricular hypertrophy. ${ }^{22}{ }^{23}$

\section{STATISTICAL METHODS}

Birth measurements were recorded in pounds and inches and tended to be rounded off, producing clumping of data; for tabulations we divided them as closely as possible into tertiles or quartiles. In regression analyses they have been used as continuous variables. All anthropometric and cardiovascular variables were normally distributed. The relation of cardiovascular variables to sex, size at birth, maternal measurements and current age, body size, smoking, and alcohol consumption were analysed by multiple linear and logistic regression, using the statistical package SPSS/PC 5.1.

\section{Results}

Eight people from the original sample of 517 had died; 435 (85\%) of the remaining 509 participated in the current study. Their characteristics are shown in table 1 . One subject declined to have arterial compliance measurements, and a further six were excluded from the analysis of the aortofemoral segment because of unsatisfactory tracings. Fifty six people were excluded from the left ventricular mass analysis, either because of an inadequate echo window $(n=54)$ or because of ventricular/valvar pathology $(n=2)$. Although $12 \%$ of the sample had to be excluded from the analysis of left ventricular mass because we were unable to obtain an adequate echocardiographic window/angle, this is a well recognised and unavoidable problem in echocardiographic studies and our percentage is comparable to values obtained in other studies. ${ }^{622}{ }^{23}$ There were no significant differences in age, sex, adult body size, and birth measurements between those who did and did not participate, or between those included and not included in the analysis. Mean blood pressures, pulse wave velocities, and left ventricular dimensions are shown in table 2 . 
Table 2 Mean (SD) blood pressures, pulse wave velocities, and cardiac dimensions

\begin{tabular}{|c|c|c|c|c|c|c|}
\hline \multirow[b]{2}{*}{ Blood pressure $(\mathrm{mm} \mathrm{Hg})$} & \multicolumn{2}{|c|}{$\begin{array}{l}\text { Men } \\
(n=237)\end{array}$} & \multicolumn{2}{|c|}{$\begin{array}{l}\text { Women } \\
(n=198)\end{array}$} & \multicolumn{2}{|c|}{$\begin{array}{l}\text { All } \\
(n=435)\end{array}$} \\
\hline & & & & & & \\
\hline Systolic & 126 & $(22)$ & 127 & (23) & 127 & $(22)$ \\
\hline Diastolic & 78 & (11) & 75 & (11) & 77 & (11) \\
\hline Mean & 96 & (15) & 95 & $(17)$ & 95 & (16) \\
\hline \multicolumn{7}{|l|}{ Pulse wave velocity $(\mathrm{m} / \mathrm{s})$} \\
\hline Aorto-right radial segment & \multicolumn{2}{|c|}{$4.32(0.45)$} & \multicolumn{2}{|c|}{$3.92(0.40)$} & \multicolumn{2}{|c|}{$4.14(0.47)$} \\
\hline Aorto-left radial segment & \multicolumn{2}{|c|}{$4.25(0.52)$} & \multicolumn{2}{|c|}{$3.87(0.43)$} & \multicolumn{2}{|c|}{$4.07(0.51)$} \\
\hline Aorto-femoral segment & \multicolumn{2}{|c|}{$3.35(0.51)$} & \multirow{2}{*}{\multicolumn{2}{|c|}{$\begin{array}{l}3.19(0.50) \\
5.63(0.58)\end{array}$}} & \multirow{2}{*}{\multicolumn{2}{|c|}{$\begin{array}{l}3.28(0.51) \\
5.71(0.64)\end{array}$}} \\
\hline Aorto-post tibial segment & 5.86 & $(0.66)$ & & & & \\
\hline \multicolumn{7}{|l|}{ Left ventricular dimensions } \\
\hline Interventricular septal thickness (mm) & 10.6 & $(1.7)$ & 9.9 & $(1.6)$ & 10.3 & $(1.7)$ \\
\hline Posterior wall thickness $(\mathrm{mm})$ & 8.8 & $(1.1)$ & 8.5 & $(0.9)$ & 8.7 & $(1.0)$ \\
\hline Left ventricular end diastolic diameter ( $\mathrm{mm})$ & 45.1 & $(4.1)$ & 42.5 & (3.5) & 43.9 & $(4.0)$ \\
\hline Left ventricular end systolic diameter (mm) & 27.3 & $(3.6)$ & 24.8 & $(2.8)$ & 26.2 & $(3.5)$ \\
\hline Left ventricular mass $(\mathrm{g})$ & 149 & (37) & 125 & $(32)$ & 138 & $(37)$ \\
\hline \multicolumn{7}{|l|}{ Left ventricular mass indexed by body } \\
\hline surface area $\left(\mathrm{g} / \mathrm{m}^{2}\right)$ & 88 & (18) & 82 & (17) & 85 & $(18)$ \\
\hline Relative wall thickness & 0.4 & $(0.06)$ & 0.4 & $(0.06)$ & 0.4 & $(0.05)$ \\
\hline
\end{tabular}

BLOOD PRESSURE

Systolic blood pressure rose with increasing age $(r=0.20, \mathrm{p}<0.0001)$, body weight $(r=0.20$, $\mathrm{p}<0.0001)$, and body mass index $(r=0.22$, $\mathrm{p}<0.0001)$. There were similar relations with diastolic blood pressure. Diastolic, but not systolic, pressure was related to adult height $(r=0.13, \mathrm{p}=0.005)$. Blood pressures were similar in men and women (table 2), and were unrelated to smoking and alcohol consumption. The 45 subjects ( 22 men and 23 women) diagnosed as having coronary heart disease in our earlier study had higher systolic blood pressures than those without the disease ( $p$ for difference $=0.05$ ).

Systolic blood pressure tended to rise with increasing birth weight (table 3) and birth length (table 4) but was unrelated to head circumference at birth. The relation with birth weight was no longer present after adjustment for adult body mass index (table 3), suggesting that it reflected the larger body mass index of people who were heavier at birth (men $r=0.12, \mathrm{p}=0.05$; women $r=0.16, \mathrm{p}=0.01)$. The relation with birth length, however, persisted (table 4). Systolic pressure rose by $1.64 \mathrm{~mm} \mathrm{Hg}$ (95\% confidence interval (CI) -0.08 to $+3.37 \mathrm{~mm} \mathrm{Hg})$ per one inch $(2.5 \mathrm{~cm})$ increase in birth length. There were similar findings for percentages of people with hypertension (table 4). These relations persisted after allowing for adult height and were similar if subjects taking antihypertensive medication $(n=58)$ were excluded from the analysis ( $p=0.08$ for the trend with birth length, allowing for adult body mass index). Because of this relation with birth length, the prevalence of hypertension rose with decreasing ponderal index (birth weight/length ${ }^{3}$ ) or head circumference:length ratio at birth $(p=0.02$ and $\mathrm{p}=0.01$, respectively). Analysis of the subgroup of 177 men and women whose mother's weight was recorded, and the 241 whose mother's pelvimetry was measured, showed no relation between blood pressure and maternal size. Adult diastolic blood pressure was unrelated to size at birth.

\section{ARTERIAL COMPLIANCE}

Pulse wave velocity rose with increasing age $(\mathrm{p}<0.0001$ for all arterial segments) and body size (weight $r=0.21-0.29$, height $r=0.13-$ 0.39 , body mass index $r=0.10-0.14$, body surface area $r=0.23-0.36 ; \mathrm{p}<0.01$ for all measurements of body size and in all arterial segments). Mean pulse wave velocity was significantly greater in men than in women (table 2). It was strongly correlated, in all arterial segments, with systolic $(r>0.25$, $\mathrm{p}<0.001)$ and diastolic $(r>0.27, \mathrm{p}<0.001)$ blood pressure. There were no significant differences in pulse wave velocities between those with and without coronary heart disease.

Table 3 Relation between cardiovascular outcome variables and birth weight

\begin{tabular}{|c|c|c|c|c|c|c|c|c|c|c|}
\hline \multirow{2}{*}{$\begin{array}{l}\text { Birth weight }(g) \\
<2400\end{array}$} & \multicolumn{2}{|c|}{$\begin{array}{l}\text { Systolic blood pressure } \\
(\mathrm{mm} \mathrm{Hg})\end{array}$} & \multicolumn{2}{|c|}{$\%$ Hypertension } & \multicolumn{2}{|c|}{$\begin{array}{l}\text { Left ventricular } \\
\text { mass indexed by } \\
\text { body surface } \\
\text { area }\left(g / m^{2}\right)\end{array}$} & \multicolumn{2}{|c|}{$\begin{array}{l}\% \text { with left } \\
\text { ventricular } \\
\text { hypertrophy }\end{array}$} & \multirow{2}{*}{ 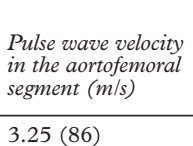 } & \multirow{2}{*}{$\begin{array}{l}\text { Pulse wave velocity in } \\
\text { the aortoposterior tibial } \\
\text { segment }(\mathrm{m} / \mathrm{s})\end{array}$} \\
\hline & 125 & (86) & & (24) & & (78) & 9 & (7) & & \\
\hline $2400-2649$ & 123 & (88) & 28 & (25) & 83 & (75) & 15 & (11) & $3.19(87)$ & $5.62(88)$ \\
\hline $2650-2834$ & 129 & (82) & 39 & (32) & 86 & (72) & 15 & (11) & $3.28(79)$ & $5.73(82)$ \\
\hline $2835-2999$ & 129 & (71) & & (23) & 85 & (63) & 11 & (7) & $3.26(69)$ & $5.64(70)$ \\
\hline $3000+$ & 129 & (108) & 31 & (33) & 89 & (91) & 21 & (19) & $3.38(107)$ & $5.84(108)$ \\
\hline All & 127 & (435) & 31 & (137) & 85 & (379) & 15 & (55) & $3.28(428)$ & $5.71(434)$ \\
\hline SD & \multicolumn{2}{|l|}{23} & \multicolumn{2}{|l|}{ - } & \multicolumn{2}{|l|}{18} & \multicolumn{2}{|l|}{ - } & 0.5 & 0.6 \\
\hline $\mathrm{p}$ Value & \multicolumn{2}{|c|}{0.1} & \multicolumn{2}{|c|}{0.9} & \multicolumn{2}{|c|}{0.05} & \multicolumn{2}{|c|}{0.06} & 0.03 & 0.05 \\
\hline${ }^{\star} \mathrm{p}$ Value & \multicolumn{2}{|c|}{0.6} & \multicolumn{2}{|c|}{0.4} & \multicolumn{2}{|c|}{-} & \multicolumn{2}{|c|}{-} & 0.8 & 0.7 \\
\hline tp Value & \multicolumn{2}{|l|}{-} & \multicolumn{2}{|c|}{-} & \multicolumn{2}{|c|}{0.2} & \multicolumn{2}{|c|}{0.08} & - & - \\
\hline
\end{tabular}

^Adjusted for age, sex, and body size; fadjusted for age and sex; figures in parentheses indicate number of subjects.

Table 4 Relation between cardiovascular outcome variables and length at birth

\begin{tabular}{|c|c|c|c|c|c|c|c|c|c|c|}
\hline \multirow{2}{*}{$\begin{array}{l}\text { Length at birth }(\mathrm{cm}) \\
<45.5\end{array}$} & \multicolumn{2}{|c|}{$\begin{array}{l}\text { Systolic blood pressure } \\
(\mathrm{mm} \mathrm{Hg})\end{array}$} & \multicolumn{2}{|c|}{$\%$ Hypertension } & \multicolumn{2}{|c|}{$\begin{array}{l}\text { Left ventricular } \\
\text { mass indexed by } \\
\text { body surface } \\
\text { area }\left(g / m^{2}\right)\end{array}$} & \multicolumn{2}{|c|}{$\begin{array}{l}\% \text { with left } \\
\text { ventricular } \\
\text { hypertrophy }\end{array}$} & \multirow{2}{*}{$\begin{array}{l}\text { Pulse wave velocity } \\
\text { in the aortofemoral } \\
\text { segment }(\mathrm{m} / \mathrm{s})\end{array}$} & \multirow{2}{*}{$\begin{array}{l}\text { Pulse wave velocity in } \\
\text { the aortoposterior tibial } \\
\text { segment }(\mathrm{m} / \mathrm{s})\end{array}$} \\
\hline & 124 & (57) & 25 & (14) & 80 & $(52)$ & 4 & (2) & & \\
\hline $45.5-46.9$ & 126 & (135) & & (36) & 85 & (119) & 12 & (14) & $3.24(132)$ & $5.66(135)$ \\
\hline $47.0-49.9$ & 126 & (134) & 33 & $(44)$ & 85 & (117) & 15 & (17) & $3.31(132)$ & $5.73(133)$ \\
\hline $50.0+$ & 132 & (105) & 39 & (41) & 88 & (87) & 23 & (20) & $3.29(104)$ & $5.77(105)$ \\
\hline All & 127 & (431) & 31 & (135) & 85 & (375) & 14 & (53) & $3.28(424)$ & $5.71(430)$ \\
\hline SD & \multicolumn{2}{|l|}{23} & \multicolumn{2}{|l|}{ - } & \multicolumn{2}{|l|}{18} & \multicolumn{2}{|l|}{-} & 0.5 & 0.6 \\
\hline $\mathrm{p}$ Value & \multicolumn{2}{|c|}{0.02} & \multicolumn{2}{|c|}{0.03} & \multicolumn{2}{|c|}{0.02} & \multicolumn{2}{|c|}{0.007} & 0.6 & 0.1 \\
\hline${ }^{\star} \mathrm{p}$ Value & \multirow{2}{*}{\multicolumn{2}{|c|}{${ }_{-}^{0.06}$}} & \multicolumn{2}{|c|}{0.07} & \multicolumn{2}{|l|}{ - } & \multirow{2}{*}{\multicolumn{2}{|c|}{0.008}} & 0.8 & 0.4 \\
\hline$t p$ Value & - & & - & & 0. & & & & - & - \\
\hline
\end{tabular}

*Adjusted for age, sex, and body size; fadjusted for age and sex; figures in parentheses indicate number of subjects. 
Table 5 Mean pulse wave velocity $(\mathrm{m} / \mathrm{s})$ according to maternal weight and pelvic size

\begin{tabular}{llll}
\hline & $\begin{array}{l}\text { Aorto-left radial } \\
\text { segment }\end{array}$ & $\begin{array}{l}\text { Aortofemoral } \\
\text { segment }\end{array}$ & $\begin{array}{l}\text { Aortoposterior tibial } \\
\text { segment }\end{array}$ \\
\hline $\begin{array}{l}\text { Maternal weight (lb) } \\
<94\end{array}$ & $4.13(44)$ & $3.35(45)$ & $5.69(45)$ \\
$94-107$ & $4.04(70)$ & $3.26(72)$ & $5.64(72)$ \\
$108+$ & $3.99(58)$ & $3.15(56)$ & $5.69(59)$ \\
All & $4.05(172)$ & $3.25(173)$ & $5.67(176)$ \\
p Value & 0.18 & 0.05 & 0.9 \\
$\star$ p Value & 0.06 & 0.01 & 0.4 \\
tp Value & 0.1 & 0.04 & 0.4 \\
External conjugate diameter $(\mathrm{cm})$ & $3.30(46)$ & $5.85(46)$ \\
$<17.8$ & $4.15(44)$ & $3.39(111)$ & $5.74(111)$ \\
$17.8-18.9$ & $4.05(107)$ & $3.25(81)$ & $5.66(84)$ \\
$19.0+$ & $3.98(81)$ & $3.32(238)$ & $5.73(241)$ \\
All & $4.05(232)$ & 0.4 & 0.1 \\
p Value & 0.09 & 0.2 & 0.05 \\
$\star$ p Value & 0.04 & & \\
\hline
\end{tabular}

^Adjusted for age, sex, and body size; tadjusted for age, sex, body size, and calculated gestational age at which the mother was weighed; figures in parentheses indicate number of subjects.

Pulse wave velocities tended to be higher in men and women with higher birth weight (table 3). After adjusting for current size, however, there were no significant relations between pulse wave velocity and any of the birth measurements (tables 3 and 4). Pulse wave velocity tended to be higher in men and women whose mothers had lower weight during pregnancy and whose mothers had smaller external conjugate diameters (table 5). Maternal weight varies with gestational age. Although the Mysore records do not contain accurate last menstrual period dates, we obtained an approximate estimate of the gestational age at which the mother was weighed by calculating how many days before delivery she attended the antenatal clinic for the first time. The relation between pulse wave velocity and maternal weight persisted even after adjusting for gestation in this way, or using a gestation adjusted maternal weight.

\section{LEFT VENTRICULAR MASS}

Left ventricular mass rose with increasing age $(r=0.11, \mathrm{p}=0.03)$ and body size (weight $r=0.62, \mathrm{p}<0.001$; height $r=0.42, \mathrm{p}<0.001$; body mass index $r=0.42, \mathrm{p}<0.001$; body surface area $r=0.64, \mathrm{p}<0.001)$. We adjusted for body size in the traditional way ${ }^{20}$ by dividing values by body surface area. The indexed left ventricular mass was higher in men than women $(p=0.001$, table 2$)$. It was strongly correlated with systolic $(r=0.45, \mathrm{p}<0.001)$ and diastolic $(r=0.36, \mathrm{p}<0.001)$ blood pressure and was higher in people with coronary heart disease (men $170 \mathrm{~g}$, women $129 \mathrm{~g}$ ) than in those without disease (men $147 \mathrm{~g}$, women $124 \mathrm{~g}$ ).

The indexed left ventricular mass and prevalence of left ventricular hypertrophy tended to be higher in those who had a higher birth weight (table 3) and longer length at birth (table 4). The relation between birth weight and left ventricular mass disappeared after adjusting for sex, reflecting the larger birth size of male babies. The relation with birth length persisted with indexed left ventricular mass rising by $1.63 \mathrm{~g} / \mathrm{m}^{2}\left(95 \%\right.$ CI 0.13 to $\left.3.13 \mathrm{~g} / \mathrm{m}^{2}\right)$ per one inch $(2.5 \mathrm{~cm})$ increase in birth length. Ventricular mass and hypertrophy were unrelated to head circumference and ponderal index at birth, or to maternal weight and pelvic diameters. Relative wall thickness, an indicator of concentric hypertrophy, was also greater in those who had been longer at birth $(p=0.01)$.

\section{Discussion}

In this group of Indian men and women, those with coronary heart disease tended to have higher systolic blood pressures and greater left ventricular mass than those without the disease. These findings are consistent with the results of studies in many other populations. In contrast to findings in Western populations, however, there was no association between these cardiovascular risk factors and small size at birth. On the contrary, mean values for systolic blood pressure and left ventricular mass were higher in people whose length at birth was greater. Arterial compliance was unrelated to birth size.

This cohort was not a true "population" sample. The study was restricted to people who were born in a single hospital in Mysore between 1934 and 1953, who were still alive, lived locally, and who gave us sufficient information to be able to match them to their birth records with certainty. Most deliveries at that time took place either at home or in the government hospital in the city. It is not clear what factors influenced these families to choose the Holdsworth Memorial Hospital for delivery. However, as it was established as a charitable mission hospital and catered to people from all socioeconomic classes, it is unlikely that this population represented a particular socioeconomic group. Many babies, especially those of low birth weight, would have died in infancy. The sample is therefore unrepresentative of all births in Mysore during that period. Although the survey was carried out in a relatively poor area of the city, just over half of our participants were from upper rather than lower social class. This may reflect greater accuracy in obtaining information for tracing and matching from this group. In spite of these deficiencies, this is a large sample of "normal" men and women. Moreover, our analysis is based on internal comparisons and bias would be introduced only if the relations between fetal growth and adult disease differed between those born in and outside the hospital, and between those traced and not traced. We have no reason to suspect such a difference. Their birth measurements were similar to those of all people born in the hospital during that period. Mean height and weight, and rates of coronary heart disease and diabetes, were similar to those reported in other urban south Indian populations. ${ }^{24-26}$ It is not possible to compare left ventricular mass and pulse wave velocity as there are no previously published data in healthy Indian adults.

The records in Mysore do not contain very accurate information on gestational age and we were unable to distinguish between low birth weight caused by prematurity and that caused by retarded fetal growth. Further, many subjects in the study were taking antihypertensive medication, including angiotensin converting enzyme inhibitors and $\beta$ blockers, which lower blood pressure, increase arterial compliance, and cause regression of left ventricular 
hypertrophy. Although these limitations may have tended to obscure any relation between small size at birth and cardiovascular risk factors in this study, similar limitations apply to many of the studies in which relations between smallness at birth and raised adult blood pressure were apparent. The sample size was similar to, or larger than, studies in Western populations which have shown significant relations between fetal growth and the cardiovascular end points we measured. ${ }^{56}$ We therefore do not believe that the results we obtained are caused by an inadequate sample size.

The average adult height of men and women in Mysore was lower than those of Western populations. A study in Sweden showed that higher blood pressure was related to small size at birth only in men who had grown into tall adults. $^{27}$ In circumstances where postnatal growth is not constrained by undernutrition, adult height is an index of genetic growth potential. Tall men who were small at birth are therefore likely to have suffered a greater degree of intrauterine growth retardation than short men. An alternative explanation is that a combination of growth retardation in utero and catch up growth postnatally is required to raise adult blood pressure. ${ }^{28}$ Median adult height in men was $166 \mathrm{~cm}$ in Mysore compared to $176 \mathrm{~cm}$ in Sweden. Poor postnatal growth may have prevented a rise in blood pressure in people of lower birth weight.

Among the group of men and women studied in Mysore, higher systolic blood pressure and greater left ventricular mass were associated with longer length at birth. The associations were not strongly significant and may have arisen by chance. Relations between blood pressure and length at birth are inconsistent between studies; both positive and negative associations have been reported. ${ }^{5} 290$ We cannot explain these differences between populations.

Arterial compliance tended to be lower in men and women born to mothers who were lighter or who had smaller pelvic diameters. Reduced external conjugate diameter is an indicator of poor nutrition during skeletal growth in childhood and adolescence. ${ }^{31}$ We speculate that maternal undernutrition compromises the ability of the fetus to sustain optimal structural development of blood vessels causing them to become stiffer and less compliant. This may help to explain findings in a recent study in Britain which showed that smaller pelvic size is associated with an increased risk of stroke in the offspring. ${ }^{32}$

In Western populations, small size at birth is associated with raised blood pressure, decreased arterial compliance, and increased left ventricular mass. ${ }^{4-6}$ It is thought that changes in levels of these risk factors may partly explain the relation between low birth weight and increased risk of coronary heart disease that has been found in many studies. ${ }^{1-3}$ In Mysore too, risk of coronary heart disease was highest in those who were small at birth. ${ }^{14}$ Our finding that small size at birth is not related to blood pressure, arterial compliance or left ventricular mass suggests that, in Indian populations at least, this increased risk is mediated by other mechanisms.

We are grateful to all the men and women who participated in our study. We thank Professor DJP Barker, director, MRC Environmental Epidemiology Unit, Southampton, for his encouragement and advice, and Dr BDR Paul, director, Holdsworth Memorial Hospital, Mysore, for his cooperation during the study. Mr Venkatachalam of medical records kindly allowed us to use the birth records. We acknowledge the help given by $\mathrm{Dr}$ SN Rajeshwar and Dr M Mahadev in tackling "difficult" echocardiograms. Significant contributions to the study were made by Miss I Annamma, Mr MN Jayakumar, Mr Tony Gerald, Mrs S Geetha, Mrs A Chachyamma, Miss M Surekha, Miss MN Swarnagowri and Ms Sarah Duggleby. Miss Vanessa Cox assisted with the computing and Mrs Jane Pearce helped with the preparation of the manuscript. The study was funded by the Wellcome Trust, Wessex Medical Trust, and DFID.

1 Osmond C, Barker DJP, Winter PD, et al. Early growth and death from cardiovascular disease in women. BMf 1993;307:1519-24.

2 Forsen T, Eriksson JG, Tuomilehto J, et al. Mother's weight in pregnancy and coronary heart disease in a cohort of Finnish men: follow up study. BM7 1997;315:837-40.

3 Rich-Edwards JW, Stampfer MJ, Manson JE, et al. Birth weight and risk of cardiovascular disease in a cohort of women followed up since 1976. BMF 1997;315:396-400.

4 Law CM, Shiell AW. Is blood pressure inversely related to birth weight? The strength of evidence from a systematic review of the literature. F Hypertens 1996;14:935-41.

5 Martyn CN, Barker DJP, Jespersen S, et al. Growth in utero, adult blood pressure and arterial compliance. Br Heart $\mathcal{F}$ 1995;73:116-21

6 Vijayakumar M, Fall CHD, Osmond C, et al. Birth weight, weight at one year, and left ventricular mass in adult life. $\mathrm{Br}$ Heart F 1995;73:363-7.

7 Barker DJP, Martyn CN, Osmond C, et al. Growth in utero and serum cholesterol concentrations in adult life. BMF 1993;307:1524-7.

8 Phillips DIW, Barker DJP, Hales CN, et al. Thinness at birth and insulin resistance in adult life. Diabetologia 1994;37: $150-4$.

9 Hales CN, Barker DJP, Clark PMS et al. Fetal and infant growth and impaired glucose tolerance at age 64 . BMF 1991;303:1019-22.

10 Barker DJP. Fetal origins of coronary heart disease. BMF 1995;311:171-4.

11 Gopalan C. Low birth weights: significance and implications. In: Sachdev HPS, Chaudhary P, eds. Nutrition in children; developing country concerns. New Delhi: Imprint, 1994:1-33.

12 Bulatao RA, Stephens PW. Global estimates and projections of mortality by cause, 1970-2015. Policy research working paper 1007. Washington, DC: Population and Human Resources Dept, The World Bank.

13 Keshavamurthy NK, Gemson K. Observations on the epidemiology of coronary heart disease from an industrial hospital. Tropical Doctor 1980;10:103-5.

14 Stein CE, Fall CHD, Kumaran K, et al. Fetal growth and coronary heart disease in South India. Lancet 1996;348: 1269-73.

15 Rose GA, Blackburn H. Cardiovascular survey methods. Geneva: World Health Organization, 1968.

16 Prineas RJ, Crow RS, Blackburn H. The Minnesota code manual of electrocardiographic findings: standards and procedures for measurement and classification. Boston: John Wright, 1982

17 DuBois D, DuBois EF. A formula to estimate the approximate surface area if height and weight be known. Arch Intern Med 1916;17:863-71.

18 Joint National Committee on Detection, Evaluation and Treatment of High Blood Pressure. Fifth report (JNCV). Arch Intern Med 1993;153:154-83.

19 Greenwald SE, Denyer HT, Sobeh MS. Non invasive measurement of vascular compliance by a photoplesythmographic technique. Proceedings of the International Society for Optical Engineering (SPIE) 1997;2970:89-97.

20 Sahn DJ, DeMaria A, Kisslo J, et al. The committee on $M$-mode standardisation of the American Society of Echocardiography. Recommendations regarding quantitation in M-mode echocardiography: results of a survey of tion in M-mode echocardiography: results of a survey of echocardio

21 Devereux RB, Alonso DR, Lutas EM, et al. Echocardiographic assessment of left ventricular hypertrophy: comparison to necropsy findings. Am f Cardiol 1986;57: 450-8.

22 Lindroos M, Kupari M, Heikkila J, et al. Echocardiographic evidence of left ventricular hypertrophy in a general aged population. Am f Cardiol 1994;74:385-90.

23 Levy D, Savage DD, Garrison RJ, et al. Echocardiographic criteria for left ventricular hypertrophy: the Framingham heart study. Am f Cardiol 1987;59:956-60.

24 Beegom R, Beegom R, Niaz MA, et al. Diet, obesity and prevalence of hypertension in the urban population of prevalence of hypertension in the urban

25 Chadha SL, Radhakrishnan S, Ramachandran K, et al. Epidemiological study of coronary heart disease in urban population of Delhi. Ind $\mathcal{F}$ Med Res 1990;92:424-30. 
26 Ramachandran A, Snehalatha C, Latha E, et al. Rising prevalence of NIDDM in an urban population in India. prevalence of NIDDM in
Diabetologia 1997;40:232-7.

27 Leon DA, Koupilova I, Lithell HO, et al. Failure to realise growth potential in utero and adult obesity in relation to blood pressure in 50 year old Swedish men. BMF 1996;312:401-6.

28 Ounsted MK, Cockburn JM, Moar VA, et al. Factors associated with the blood pressures of children born to women who were hypertensive during pregnancy. Arch Dis Child 1985;60:631-5
29 Barker DJP, Godfrey KM, Osmond C, et al. The relation of fetal length, ponderal index and head circumference to blood pressure and the risk of hypertension in adult life. blood pressure and the risk of hypert

30 Law CM, Barker DJP, Bull AR, et al. Maternal and fetal influences on blood pressure. Arch Dis Child 1991;66:1291-5.

31 Nicholson C, Allen HS. Variation in the female pelvis. Lancet 1946;ii:192-5.

32 Martyn CN, Barker DJP, Osmond C. Mothers' pelvic size, fetal growth, and death from stroke and coronary heart disease in men in the UK. Lancet 1996;348:264-8.

\section{IMAGES IN CARDIOLOGY}

\section{Growth and the implantable cardioverter defibrillator}

A defibrillator using high voltage pericardial patches was implanted in a 30 month old girl with the long QT syndrome and out of hospital cardiac arrest despite $\beta$ blockers (left). During the first three years she remained well on atenolol $25 \mathrm{mg}$ twice daily with no shocks or syncope. She then had five successive shocks within two weeks because of inappropriate $\mathrm{T}$ wave sensing. A chest $x$ ray revealed that owing to growth the pericardial patches had been displaced upwards and were positioned across the atria (right). It could not be certain that the patches were in a satisfactory position to defibrillate the ventricles. In addition, the ventricular lead had lost its original atrial loop and was stretched across the tricuspid valve. The

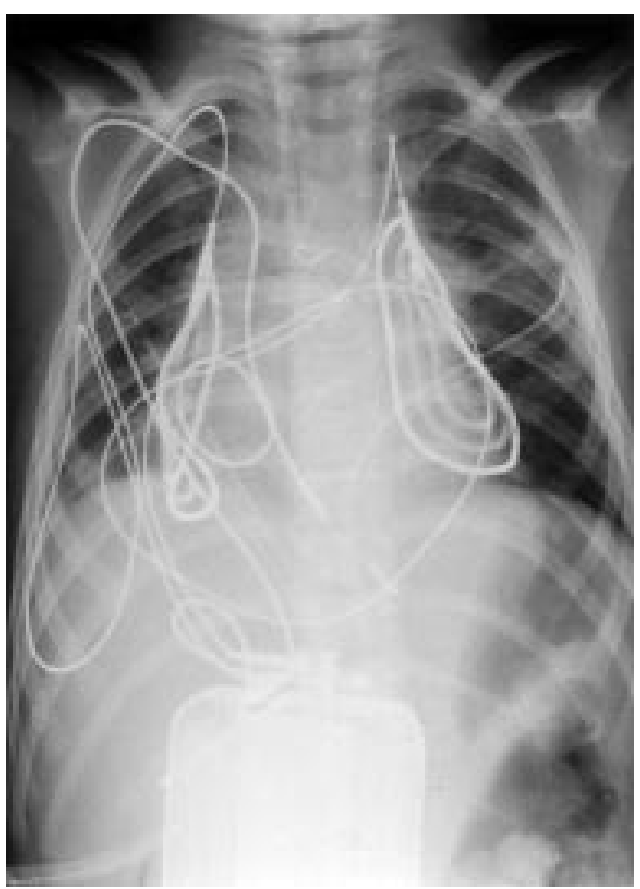

defibrillator was therefore revised to a transvenous system using a single $9 \mathrm{~F}$ pacing/ sensing/defibrillator lead, and the lead tunnelled to an active generator implanted in the abdomen. The pericardial patches were left in situ to avoid thoracotomy. Defibrillation thresholds between the abdominal generator and ventricular lead were 10-15 Joules.

Our patient illustrates that growth affects external cardiac patches as well as transvenous leads, and the positions of both should be monitored at regular intervals by chest radiography. With the development of smaller leads and active generators, transvenous implantable cardioverter defibrillator systems can be used even for small children.

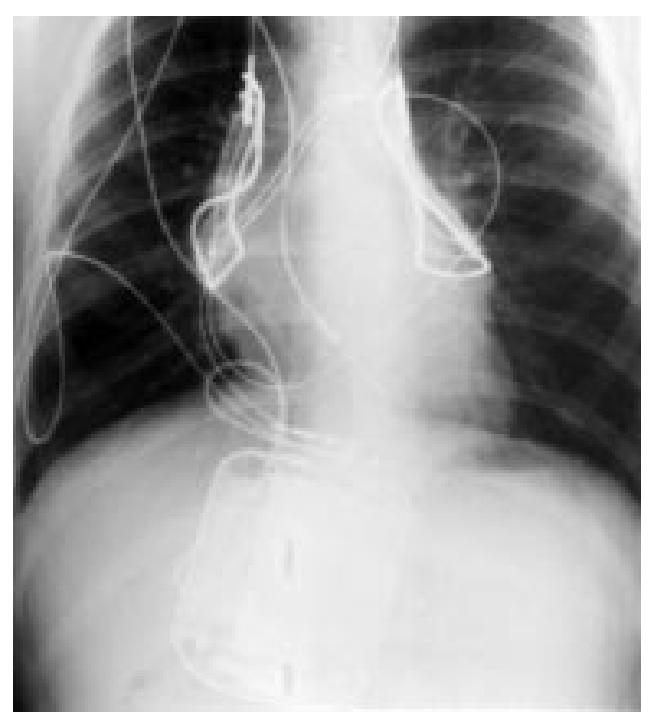

K A MCLEOD

A RANKIN

J POLLOCK 